\title{
Direct Heterogeneous Electron Transfer of Theophylline Oxidase.
}

\author{
Andreas Christenson, Eva Dock, Lo Gorton and Tautgirdas Ruzgas* \\ Department of Analytical Chemistry, Lund University, P.O. Box 124, SE-221 00 Lund, \\ Sweden
}

\begin{abstract}
Direct electron transfer (DET) was shown between the heme containing enzyme theophylline oxidase (ThO) and the surface of both graphite and gold electrodes. As proof on graphite a steady state current for theophylline was recorded using the electrode modified with adsorbed ThO. The electrode showed a Michaelis-Menten like response to theophylline with a detection limit of $0.2 \mathrm{mM}$ and a Michaelis-Menten constant equal to $3.2 \mathrm{mM}$. These initial results open up a possibility for the development of reagentless third generation biosensor based on heterogeneous DET between ThO and an electrode. On gold DET between ThO and the surface of aldrithiol-modified gold was studied with spectroelectrochemical measurements. DET was observed for soluble ThO as a change of its spectrum in a gold capillary responding to a change in the applied potential. It was shown that the redox conversion of the heme domain of the enzyme is directly (mediatorlessly) driven by the potential applied at the gold electrode. The measurements enabled an estimation of the formal potential $\left(E^{\circ}\right)$ of the redox process equal to $-275 \pm 50 \mathrm{mV}$ vs. $\mathrm{Ag} \mid \mathrm{AgCl}_{\text {sat }}$ at $\mathrm{pH}$ 7.0. The experimentally determined number of the electrons involved in this heterogeneous electron transfer process was estimated to be equal to 0.53 . The low precision in determination of the $E^{\circ}$, and the value of the number of electrons lower than one indicate that kinetic restrictions disturbed the evaluation of the true thermodynamic values from relatively fast spectroelectrochemical measurements.
\end{abstract}


Keywords: Direct electron transfer, enzyme electrode, biosensor, theophylline detection, amperometry. spectroelectrochemistry

*Corresponding author: Tautgirdas Ruzgas, Department of Analytical Chemistry, Lund University, S-221 00 Lund, Sweden. Tel.: +46-46-222-8191; fax: +46-46-222-4544;

e-mail: Eva.Dock@analykem.lu.se 


\section{Introduction}

Theophylline oxidase (ThO) is a heme containing enzyme that was shown to be able to communicate with ferricytochrome $c$ (Gupta, et al., 1988) acting as a natural electron acceptor, reaction (1). The substrate, theophylline, is oxidised by ThO to form 1,3dimethyluric acid. The reduced enzyme can then in turn be reoxidised by transferring its charge to ferricytochrome $c$ according to;

theophylline +2 ferricytochrome $c \stackrel{\text { ThO }}{\longrightarrow} 1,3$ - dimethyluric acid +2 ferrocytochrome $c$ (1)

The efficient electron transfer from the reduced enzyme to ferricytochrome $c$ means that ThO has an electron transfer pathway connecting the active site with the enzyme surface. Previously, several reports pointed out that enzymes known to readily exchange electrons with cytochrome $c$ (cyt. c) also show efficient electron transfer with electrodes, e.g., cytochrome $c$ peroxidase, cytochrome $b_{2}$, cellobiose dehydrogenase, laccase and sulphite oxidase (Jin, et al., 1996, Fridman, et al., 2000, Ferapontova et al., 2003). In several additional cases researchers have proved that the natural electron acceptor/donor can be replaced by an electrode surface for some other redox enzymes, showing that a direct electronic communication can also occur between a redox enzyme and an electrode (Tarasevich, et al., 1979, Yaropolov, et al., 1979, Ghindilis, et al., 1997, Armstrong and Wilson, 2000). For heme containing redox enzymes, direct electron transfer (DET) between the heme group and the electrode has been postulated and in many cases demonstrated (Gorton, et al., 1999). The two properties of ThO, (i) its fast redox reaction with cyt. $c$ and (ii) being a heme containing enzyme, made us investigate whether direct electron communication of ThO with an electrode was feasible. In this work experimental data indicating a direct coupling/contact between $\mathrm{ThO}$ and graphite are presented in the presence of the enzyme substrate, theophylline. Additionally, experimental data for DET between ThO and aldrithiol modified gold are presented in the absence of theophylline and these results are complemented by spectrophotometric measurements.

From an analytical point of view what makes theophylline an important analyte is that it is a drug that is widely used in the treatment of asthmatic and other bronchospastic diseases (Kawai and Kato, 2000, Rowe, et al., 1988). The therapeutic window for theophylline in serum is narrow, 10 to $20 \mathrm{mg} / \mathrm{l}$ (Jackson, et al., 1973). In the case of too low a concentration 
the drug is ineffective, whereas if it exceeds the upper limit the drug will accumulate and become toxic. Thus, it is of great interest to develop methods for rapid and highly selective theophylline detection. Moreover, theophylline is an established "probe drug" to evaluate the drug metabolising enzyme activity of both man and animals (Elsheikh, et al., 2001) thus making it a key analyte in pharmaceutical studies.

Several methods for theophylline detection have been developed including gas and liquid chromatography, UV spectrophotometry and immunoassays (Kaplan and Pesce, 1984, Rowe, et al., 1988). A ThO-based kit for spectrophotometrical detection of theophylline based on reaction (1) is commercially available from GDS Technology Inc. (Elkhart, IN, USA) (Decastro, et al., 1989). Among bioprobe based systems, an electrode modified with microbial xanthine oxidase (Stredansky, et al., 2000) and an assay based on theophylline inhibition of bovine liver alkaline phosphatase (Foulds, et al., 1990) have been reported. Amperometric enzyme electrodes modified with ThO for measuring theophylline directly in serum could be an alternative to enable rapid and continuous monitoring. Previously, only two articles have been published on ThO immobilised on electrodes, in both cases the electronic coupling between the enzyme and the electrode was realised by redox mediators, i.e., mediated ET. Wang et al. entrapped the enzyme together with cyt. $c$ within a Nafion layer on platinum (Wang, et al., 1991). In this construction, a second redox mediator, $\mathrm{Fe}(\mathrm{CN})_{6}{ }^{4-}$, was used shuttling the electrons between cyt. $c$ and the electrode (at $+0.4 \mathrm{~V} v s$.

$\mathrm{Ag} \mid \mathrm{AgCl}$ ). McNeil and coworkers (McNeil, et al., 1992) on the other hand described two approaches to construct electrodes, where cyt. $c$ was replaced by non-physiological mediators. In one prototype ferrocene monocarboxylic acid was tested and in another the organic conducting salt NMPTCNQ was used. For both of these approaches an applied potential of $+0.1 \mathrm{~V} v s$. $\mathrm{Ag} \mid \mathrm{AgCl}$ was used.

\section{Experimental}

\subsection{Reagents}

The kit containing theophylline oxidase (ThO, $14 \mathrm{U} / \mathrm{ml}$ ) was obtained from GDS Diagnostics (Elkhart, IN, USA). Horse heart cytochrome $c$ (cyt. $c$ ) and theophylline were from Sigma (St. Louis, MO, USA). The buffer salts $\left(\mathrm{Na}_{2} \mathrm{HPO}_{4}\right.$ and $\left.\mathrm{NaH}_{2} \mathrm{PO}_{4}\right)$, sulphuric acid and hydrogen peroxide were obtained from Merck (Darmstadt, Germany). Aldrithiol-4 (4,4'-dipyridyl 
disulfide) was obtained from Aldrich (Dorset, UK). The water used in all experiments was purified with a Milli-Q system (Millipore, Bedford, USA). Test solutions of theophylline were prepared daily in buffer from a stock solution $\left(10 \mathrm{mM}\right.$ in water, stored at $\left.+4^{\circ} \mathrm{C}\right)$.

\subsection{Measurements with graphite electrodes}

The electrodes were prepared using rods cut from solid spectroscopic graphite (SGL Carbon, Werke Ringsdorff, Bonn, Germany, type RW001, $3.05 \mathrm{~mm}$ diameter). The cross section surfaces were polished on wet fine-structured emery paper (Tufbak Durite, P1200), which resulted in a disk graphite electrode with a geometric surface area of $0.072 \mathrm{~cm}^{2}$. After polishing the electrode was carefully rinsed with Milli-Q water and let to dry in air. A volume of $5 \mu \mathrm{l}$ of theophylline oxidase solution $(0.07 \mathrm{U})$ was added to the polished electrode surface. Adsorption was allowed to proceed for $20 \mathrm{~min}$ at room temperature before the electrode was rinsed with Milli-Q water to remove remaining enzyme solution. This enzyme modification process was repeated additionally twice with the anticipation that a ThO monolayer concentration on the electrode surface was sufficient to register a direct ET.

The enzyme modified electrode was placed into a Teflon holder and inserted into a flowthrough wall-jet amperometric cell (Appelqvist, et al., 1985) with an $\mathrm{Ag} \mid \mathrm{AgCl}(0.1 \mathrm{M} \mathrm{KCl})$ reference electrode and a platinum wire auxiliary electrode. The electrodes were connected to a three-electrode potentiostat (LC-4C, BAS, Bioanalytical Systems, West Lafayette, IN, USA) connected to a strip chart recorder (Kipp \& Zonen, Delft, Netherlands). The amperometric cell was connected to a single-line flow system and a peristaltic pump (Minipuls 2, Gilson, Worthington, OH, USA) generated a flow $(0.4 \mathrm{ml} / \mathrm{min})$ of degassed phosphate buffer $(50 \mathrm{mM}, 6<\mathrm{pH}<8)$. The bioelectrocatalytic current response for theophylline was recorded by steady state measurements at potentials between $-0.1 \mathrm{~V}$ and $+0.3 \mathrm{~V}$ vs. $\mathrm{Ag} \mid \mathrm{AgCl}(0.1 \mathrm{M} \mathrm{KCl})$.

\subsection{Spectroelectrochemical measurements with gold capillary electrode}

Direct electron transfer between ThO and a thiol-modified gold electrode was investigated by using a gold capillary spectroelectrochemical cell. The cell was previously described elsewhere (Larsson, et al., 2001). Some essential modifications, however, have been made to the previous design of the cell, which are shown in Fig. 1. Briefly, the spectroelectrochemical cell consists of a $1 \mathrm{~cm}$ long gold capillary electrode with an inner diameter of $350 \mu \mathrm{m}$. To 
record a spectrum of a solution inside the spectroelectrochemical cell, at the ends of the capillary, input and output optical fibres FCB-UV 400/050-2 and FC-UV 200, respectively, are placed. The light source DH-2000, spectrometer SD 2000 and the analog to digital conversion board ADC-500, which constitute the Ocean Optics Spectrometer (Dunedin, FL, USA), have been used. The spectrometer is driven by a computer software Spectra Win 4.2 from TOP Sensor System (Eerbreek, The Netherlands). The cell is equipped with an $\mathrm{Ag}|\mathrm{AgCl}| \mathrm{KCl}_{\text {sat }}$ reference electrode from Cypress Systems Inc. (Lawrence, KS, USA) and two Pt wires situated at each capillary end serve as a single counter electrode. The potential of the gold capillary is controlled by a potentiostat CV-50 W from BAS (West Lafayette, IN, USA). In spectroelectrochemical measurements, i.e., electrochemical titration of the redox protein, approximately $20 \mu \mathrm{l}$ of protein solution was aspirated through the capillary to replace the buffer solution of the cell with the solution of the redox protein.

Before any spectroelectrochemical measurements the capillary of the spectroelectrochemical cell was cleaned and modified with aldrithiol-4. For this, the gold capillary was initially immersed into the solution of sulphuric acid and hydrogen peroxide in proportion 3:1 by volume. After that the capillary was rinsed with deionised water and immersed into a saturated solution of aldrithiol-4 in water (1.5 mg of aldrithiol-4 per $\mathrm{ml}$ ) for $30 \mathrm{~min}$ followed by a second careful rinsing with deionised water.

Cyt. $c$ was dissolved in $0.02 \mathrm{M}$ phosphate buffer ( $\mathrm{pH}$ 7) containing $0.1 \mathrm{M} \mathrm{KCl}$ and was used as a standard for testing the spectroelectrochemical cell and for the correctness of the electrochemical titration. For spectroelectrochemical measurements the ThO solution (14 U per $\mathrm{ml}$ ) was initially dialysed against $0.02 \mathrm{M}$ phosphate buffer $(\mathrm{pH} 7)$ containing $0.1 \mathrm{M} \mathrm{KCl}$ at $+4^{\circ} \mathrm{C}$ overnight. For dialysis osmotic film filters (MWCO 3500) from Pierce (Rockford, USA) were used.

To calculate the formal potential, $E^{\circ}$, and the number of electrons, $n$, characterising the heterogeneous ET of cyt. $c$ and $\mathrm{ThO}$ at the gold surface, the data from the spectroelectrochemical measurements were treated using a combination of the following equations. Firstly, Nernst equation (2) provides $E^{\circ}$ and $n$ if equilibrium concentrations of the oxidised, $C_{\text {ox }}$, and reduced, $C_{\text {red }}$, species are known at different electrode potentials, $E$, 
$E=E^{\circ}+\frac{R T}{n F} \ln \frac{C_{o x}}{C_{r e d}}$

where $F$ is Faradays constant, $R$ is the gas constant and $T$ is the absolute temperature. Secondly, the concentrations $C_{\mathrm{ox}}$ and $C_{\text {red }}$ are determined from absorption measurements according to Lambert Beer's law:

$A=\varepsilon \cdot C \cdot L$

where $A$ is the absorbance, $\varepsilon$ is the extinction coefficient for the species at a specific wavelength and $L$ is the length of the optical pathway in the spectroelectrochemical cell. At any potential the absorbance that is measured can be regarded as the sum of absorbance values originating from the reduced and oxidised forms of the proteins as represented in Eq. (4).

$A_{\text {mix }}=\varepsilon_{o x} \cdot C_{o x} \cdot L+\varepsilon_{\text {red }} \cdot C_{r e d} \cdot L$

To derive the individual concentrations of the redox forms of the protein from absorbance measurements of the mixture of reduced and oxidised protein knowledge on the spectra and extinction coefficients for the pure oxidised and pure reduced compounds are needed. These values were measured at extreme applied potentials (at +0.3 and $-0.6 \mathrm{~V}$ vs. $\mathrm{Ag} \mid \mathrm{AgCl} \mathrm{sat}_{\mathrm{sa}}$, respectively) to ensure that all protein molecules (cyt. $c$ or $\mathrm{ThO}$ ) are in their oxidised or reduced form, respectively. These measurements give additional absorbance values that can be represented by the following two equations:

$A_{o x, S}=\varepsilon_{o x} \cdot C \cdot L$

$A_{\text {red }, S}=\varepsilon_{\text {red }} \cdot C \cdot L$

where $A_{o x, S}$ and $A_{\text {red,S }}$ are absorbance values for the fully oxidised and fully reduced enzyme in gold capillary cell, whereas $C$ represents the total concentration of the protein in the solution. These two additional equations enable excluding $\varepsilon_{0 x}$ and $\varepsilon_{\text {red }}$ from Eq. (4) and thus providing a final working equation (Eq. (7)) for determining the concentrations of $C_{\mathrm{ox}}$ and $C_{\text {red }}$ at any applied potential:

$$
\frac{A_{\text {mix }}}{A_{\text {red }, S}}=\frac{A_{o x, S}}{A_{\text {red }, S}} \cdot \frac{C_{o x}}{C}+\frac{C_{r e d}}{C}
$$

Plotting $A_{\text {mix }} / A_{\text {red,S }} v s . A_{\text {ox }, \mathrm{S}} / A_{\text {red,S }}$ measured from the recorded spectra at different wavelengths gives a linear dependence, where the slope and the intercept are proportional to $C_{\mathrm{ox}}$ and to $C_{\text {red, }}$ respectively. After the slope and intercept values have been determined at different 
potentials a plot corresponding to $E v s . \ln \left(\mathrm{C}_{\mathrm{ox}} / \mathrm{C}_{\text {red }}\right)$ is constructed enabling calculation of $E^{\circ}$, and $n$ according to Nernst equation, Eq. (2). In all plots experimental data were fitted using the linear least squares procedure available in the graphical software Sigma Plot. The adsorption values at the following wavelengths have been used for the mentioned calculations: $402.5,410.0,413.8$, and $414.9 \mathrm{~nm}$.

\section{Results and Discussion}

\section{ThO-modified graphite electrodes}

Initial attempts were made to evaluate any response for theophylline at the ThO modified electrodes by placing them in a flow through amperometric cell connected to a flow injection system. However, it appeared that when injecting a sample containing $1 \mathrm{mM}$ theophylline into the flow system anodic current peaks were registered for ThO modified electrodes $(\sim$ $+12 \mathrm{nA})$ and cathodic peak currents for bare graphite electrodes $(\sim-83 \mathrm{nA})$, followed by a transient signal in the reverse direction for bare as well as ThO modified electrodes. Aromatic molecules in general are known to have a pronounced tendency to strongly adsorb on graphite electrodes causing capacitive current changes during the course of adsorption/desorption and for theophylline and structurally related compounds it is a well known fact they have a strong tendency to adsorb on carbon electrodes especially on graphite (Dryhurst, 1977). It was concluded that theophylline strongly interacts with the graphite surface causing these non-faradaic response peaks.

To separate the capacitive from faradaic current the following measurement procedure has been conducted. Instead of injecting discrete small samples containing theophylline, the carrier buffer with increasing concentrations of theophylline was allowed in the steady state mode to pass bare as well as ThO modified electrodes. For ThO modified electrodes, initially a peak shaped anodic response was observed right after exchanging pure phosphate buffer for a theophylline containing buffer solution into the cell as shown in Fig. 2. The peak current gradually declined and a stable current could be recorded indicating a response for theophylline caused by its oxidation by ThO. When changing back to pure buffer a cathodic response peak could be seen before a stable baseline was reached with a value equivalent to the initial background current (see Fig. 2). The non-faradaic effect was reversible and the desorption time was the same $(\sim 5 \mathrm{~min})$, independent of the used theophylline concentrations. 
For bare graphite instead an initial cathodic current was seen when the buffer was exchanged for the theophylline containing solution. This current then gradually decreased to coincide with the value for the initial baseline registered for pure phosphate buffer, i.e., no net current plateau as for the ThO modified electrode could be seen. An anodic peak was observed when changing back to pure buffer for the bare electrode before a stable baseline was reached as for the ThO modified electrode.

To determine the appropriate working conditions for the ThO modified electrode, the steady state current response for $1 \mathrm{mM}$ theophylline, taken as the difference between the background current and the steady state plateau value (see Fig. 2), was registered between pH 6 and 8 as well as for different applied potentials. From the results it was clear that a $\mathrm{pH}$ value close to 7 was a good choice (Table 1), which is in agreement with both previous work with ThO modified electrodes (Wang, et al., 1991) and with the theophylline enzyme kit. When the effect of the applied potential was investigated, an independence of the intensity of the steady state current for theophylline and the applied potential was registered for potentials between 0.1 and $+0.2 \mathrm{~V}$ vs. $\mathrm{Ag} \mid \mathrm{AgCl}$. The $E^{\circ}$ of the cytochrome domain of many of the heme containing redox enzymes at $\mathrm{pH} 7$ is found below $0 \mathrm{~V} \mathrm{Ag} \mid \mathrm{AgCl}$ (Gorton et al., 1999; Schuhmann et al. 2000; Lindgren et al., 2000; Aguey-Zinsou et al., 2003; Ferapontova, 2003). The $E^{\circ}$-value of the heme in ThO is not to be found in the literature but should be lower than that of cyt. $c$ as the reaction rate between reduced ThO and cyt. $c$ is very high. As shown below the $E^{\circ}$-value of the heme of $\mathrm{ThO}$ evaluated spectroelectrochemically on aldrithiol modified gold is around $-0.28 \mathrm{~V}$ vs. $\mathrm{Ag} \mid \mathrm{AgCl}$ and it is anticipated that its value does not deviate too much when ThO is adsorbed on graphite. The $E^{\circ}$ of cyt. $c$ is around 0 $\mathrm{mV}$ vs. $\mathrm{Ag} \mid \mathrm{AgCl}$ and therefore, if DET from reduced $\mathrm{ThO}$ and graphite were to occur, response currents for theophylline are expected at potentials at least in the range of that of the $E^{\circ}$ ' of cyt. $c$ and higher, which is also the case for the ThO modified electrodes. It is therefore anticipated that if the DET between ThO and the electrode occurs through the heme group that the response to theophylline would be independent on the applied potential as long as it is sufficiently more positive than the $E^{\circ}$-value of the heme group.

The reasons for the low response current are probably that the surface coverage of active enzyme is low in combination with random adsorption of the enzyme on the graphite surface leading to a low fraction of the adsorbed and active ThO molecules oriented on the electrode surface for an efficient direct heterogeneous electron transfer between the enzyme and 
graphite. A potential of $+0.1 \mathrm{mV} v s . \mathrm{Ag} \mid \mathrm{AgCl}$ was chosen for further experiments. At this potential the steady state current plateau for theophylline could only be seen when the electrode surface was modified with $\mathrm{ThO}$, i.e., the only registered faradaic electrode reaction of theophylline was registered as a consequence of the reaction catalysed by $\mathrm{ThO}$.

The repeatability and the reproducibility of the measurements were determined for $1 \mathrm{mM}$ theophylline at the ThO modified electrode at the chosen conditions for further measurements, i.e., at $\mathrm{pH} 7$ and $+0.1 \mathrm{~V}$ vs. $\mathrm{Ag} \mid \mathrm{AgCl}$. The steady state current for three independent measurements using the same electrode varied between 1.3 and $1.45 \mathrm{nA}$. The steady state current for measurements using three equivalently prepared electrodes varied between 1.3 and $2.2 \mathrm{nA}$. The higher variation between the currents presented between different electrodes probably depends on the variation that occurs when using such low concentrations of $\mathrm{ThO}$ when immobilising the enzyme on the graphite electrodes. These preliminary results, however, only point to the fact that direct electron transfer occurs. Improved repeatability and reproducibility are topics that will be the subject for further investigations.

Figure 3 shows a calibration curve obtained for steady state currents (see D in Fig. 2) measured for different theophylline concentrations with one ThO modified electrode at an applied potential of $+0.1 \mathrm{~V} v s . \mathrm{Ag} \mid \mathrm{AgCl}$. The steady state current related to the theophylline concentration clearly follows a typical Michaelis-Menten behaviour, which is valid when the current is not controlled by mass transfer (Shu and Wilson, 1976; Kamin and Wilson, 1980),

$$
I=I_{\max }[S] /\left([S]+K_{M}^{a p p}\right)
$$

where $I$ is the registered response current, $S$ is the substrate concentration, $I_{\max }$ the current when the enzyme is substrate saturated, and $K_{M}^{a p p}$ the apparent Michaelis-Menten constant defined as the substrate concentration when $I=I_{\max } / 2 . I_{\max }$ was estimated to $9.2 \mathrm{nA}$ and $K_{M}^{a p p}$ to $3.2 \mathrm{mM}$ through direct fitting the experimental values to Eq. (8). The detection limit (defined as three times the noise) was estimated to $0.2 \mathrm{mM}$ theophylline. The results demonstrate that a DET is established between $\mathrm{ThO}$ and graphite. A very schematic mechanism of the DET between ThO and graphite is presented in Fig. 4. 


\section{Spectrelectrochemistry of ThO on aldrithiol modified gold electrode}

In many of the previous initial claims for DET communication between a redox enzyme and an electrode only indirect proofs prevail, i.e., only in the presence of the enzyme substrate indications of direct electron transfer can be seen (Gorton et al., 1999). However, when exchanging graphite for, e.g., thiol modified gold, independent electrochemical proofs, i.e., in the absence of enzyme substrate, true mediatorless electron transfer has been shown for, e.g., cellobiose dehydrogenase (Lindgren, et al., 2000), alcohol PQQ dehydrogenase (Schuhmann, et al., 2000), sulphite oxidase (Ferapontova et al., 2003) and sulphite dehydrogenase (AgueyZinsou et al., 2003). Since ThO in our experiments seems to communicate with the graphite surface with slow heterogeneous kinetics, $\mathrm{CV}$ experiments in the absence of substrate have not yet exhibited any clear results. Combining an additional technique such as spectroscopy with electrochemistry largely increases the possibility to follow the electron transfer characteristics between the redox enzyme and the electrode (Larsson, et al., 2001). Therefore, the DET characteristics between $\mathrm{ThO}$ and gold were studied with spectroelectrochemistry to confirm the initial results on DET between ThO and graphite reported on above.

In our previous publications we have demonstrated that spectroelectrochemical measurements of redox proteins can be efficiently carried out using a gold capillary electrode (Larsson, et al., 2001, Bistolas et al., 2004, Ferapontova et al., 2004). However, due to the fact that the thin capillary of gold is very soft, the handling of the cell was initially difficult. To make the cell more robust some important modifications have been made to its construction as reflected in Fig. 1. First, the capillary was made by drilling a $350 \mu \mathrm{m}$ hole through a $1 \mathrm{~cm}$ long gold rod with an outer diameter of $3 \mathrm{~mm}$. Such a construction excluded problems with capillary deformations, which were encountered in the old construction of the cell (Larsson et al., 2001). The second important improvement of the cell was the establishment of the self-centration of the capillary to the light part of the spectroelectrochemical cell. This was realised by making the ends of the gold rod conical and exploiting commercial T-crossings for connecting the optical fibres to the ends of the gold capillary. These two improvements made the spectroelectrochemical cell robust, easy to handle and useable by less experienced persons. The described spectroelectrochemical cell (Fig. 1) was used in all spectroelectrochemical measurements of ThO and cyt. $c$. 
The first objective in the study of heterogeneous ET characteristics of ThO was to determine whether DET is possible between ThO and the surface of a gold electrode. For this the solution of ThO was injected into the aldrithiol modified gold capillary cell and spectra were recorded at different potentials applied to the capillary electrode. A few examples of the spectra are presented in Fig. 5, from which it can be concluded that clear changes of the spectrum occur at different applied potentials indicating that mediatorless DET between the aldrithiol modified gold electrode and ThO is observed. Comparing the spectra with those of oxidised and reduced cyt. $c$ (see Fig. 5 insert) allows to conclude that the heme domain of ThO is fully oxidised at $0 \mathrm{~V}$ and fully reduced at $-0.6 \mathrm{~V} v s$. $\mathrm{Ag} \mid \mathrm{AgCl}_{\text {sat }}$. From these date it can be stated that the observed redox reaction of $\mathrm{ThO}$ at aldrithiol modified gold is a redox transformation of the heme according to reaction (9).

$\mathrm{ThO}\left(\right.$ heme $\left.-\mathrm{Fe}^{3+}\right)+\mathrm{ne}^{-} \leftrightarrow \mathrm{ThO}\left(\right.$ heme $\left.-\mathrm{Fe}^{2+}\right)$

The next objective of the experimental work was to determine the $E^{\circ}$ and the $n$ characterising the heterogeneous redox reaction (reaction (9)) of ThO. Spectra similar to those presented in Fig. 5 were recorded at different potentials and the absorbance values at various wavelengths were used to calculate the ratio $C_{o x} / C_{r e d}$ corresponding to a certain applied potential. The final result is presented in Fig. 6 as the electrochemical titration plot exhibiting the variation of the applied potential $v s . \ln \mathrm{C}_{\mathrm{ox}} / \mathrm{C}_{\text {red }}$. Theoretically, the plot should be a linear $E v s . \ln \mathrm{C}_{\mathrm{ox}} / \mathrm{C}_{\text {red }}$ dependence as is experimentally shown for the case of the electrochemical titration of cyt. $c$ (Fig. 6). The non-linearity of the plots in case of ThO is, however, obvious with some bend between -0.2 and $-0.4 \mathrm{~V}$. Due to insufficient linearity of the electrochemical titration plots (Fig. 6) only a rough estimation of the $E^{\circ}$ ' of ThO can be

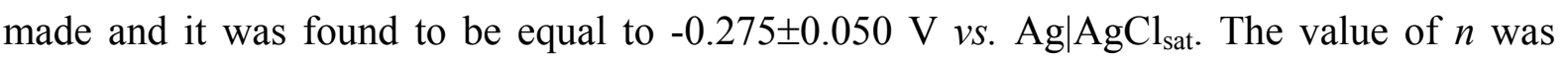
found to be equal to 0.53 , which is also considered as an underestimation due to the nonlinearity of the electrochemical titration plots. The low precision and accuracy in the evaluation of the thermodynamic data $\left(E^{\circ}\right.$ and $\left.n\right)$ from the spectroelectrochemical measurements of the redox conversion of $\mathrm{ThO}$ are ascribed to slow heterogeneous ET kinetics. The sluggishness of the ET process can possibly be caused by the fact that ThO is a membrane bound enzyme and detergents are used for its solubilisation. Enzyme-detergent micelles will be present even in the case of the dialysed enzyme solution thus possibly 
shielding the enzyme from making a sufficient intimate electronic electrode-enzyme contact for a Nernstian behaviour.

\section{Concluding remarks}

The experimental results on the electrochemistry of ThO on graphite and gold electrodes presented in this report provide proofs, indirect when adsorbed on graphite, and direct on the surface of aldrithiol-modified gold, for a heterogeneous DET process between ThO and the electrode. To facilitate further development of ThO based electrodes it is essential to acquire more knowledge about the enzyme and its electrochemistry. The structure and the basic biochemical characterisation of ThO remain unknown. Using solutions with higher concentrations of ThO and containing less amounts of detergents would be beneficial and electrochemical experiments including spectroelectrochemical measurements at gold electrodes modified with thiol mixtures or thiols bearing differently charged head groups could be suggested for optimising the DET reaction between the ThO and the surface of the electrodes, thus, probably enabling better accuracy and precision of the thermodynamic redox characteristics from spectroelectrochemical measurements. Additionally a positive effect of exploiting and optimising DET of enzymes in biosensor development is, first of all, higher selectivity. At least this is expected and in some cases it has been experimentally demonstrated (Dock, et al., 2001).

\section{Acknowledgements}

The authors thank Dr. Annika Lindgren-Sjölander for her help during the course of the work and the European Commission (project QLK3-2000-01481 "INTELLISENS"), The Swedish Research Council (VR) and The Crafoord Foundation, Lund, Sweden, for financial support. 


\section{References}

Aguey-Zinsou, K.-F., Bernhardt, P. V., Kappler, U., McEwan, A. G., 2003, Direct electrochemistry of a bacterial sulfite dehydrogenase, J. Am. Chem. Soc., 125, 530535.

Appelqvist, R., Marko-Varga, G., Gorton, L., Torstensson, A. and Johansson, G., 1985, Enzymic determination of glucose in a flow system by catalytic oxidation of the nicotinamide coenzyme at a modified electrode, Anal. Chim. Acta, 169, 237-247.

Armstrong, F. A. and Wilson, G. S., 2000, Recent developments in faradaic bioelectrochemistry, Electrochim. Acta, 15-16, 2623-2645.

Bistolas, N., Christenson, A. Ruzgas, T., Jung, C., Scheller, F. W. and Wollenberger, U., 2004. Spectroelectrochemistry of cytochrome P450cam, Biochem. Biophys. Res. Commun., 314, 810-816

Christenson, A. and Ruzgas, T., 2004, Direcdt heterogeneous electron transfer of theophylline oxidase. Part II: spectroelectrochemical evidence. Biosens. Bioelectron., submitted.

Decastro, A. F., Gupta, S. K. and Agarwal, A. K., 1989, Enzymic determination of theophylline, (GDS Technology, Inc., USA), PCT Int. Appl. 8907653.

Dock, E., Lindgren, A., Ruzgas, T. and Gorton, L., 2001, Effect of interfering substances on current response of recombinant peroxidase and glucose oxidase-recombinant peroxidase modified graphite electrodes, Analyst, 126, 1929-1935.

Dryhurst, G., 1977, Electrochemistry of biological molecules, Academic Press, New York.

Elsheikh, H. A., Ali, B. H., Zahurin, M., Mustafa, A. M., Alhadrami, G. and Bashir, A. K., 2001, Comparative pharmacokinetics of theophylline in camels (Camelus dromedarius) and goats (Caprus hircus), J. Vet. Med. A. Physiol. Pathol. Clin. Med., 48, 581-586.

Ferapontova, E. E., Ruzgas T., Gorton, L., 2003, Direct electron transfer of heme- and molybdopterin cofactor-containing chicken liver sulfite oxidase on alkanethiolmodified gold electrodes. Anal. Chem., 75, 4841-4850.

Ferapontova, E. E., Christenson, A., Hellmark, A. and Ruzgas T., 2004. Spectroelectrochemical study of heme- and molybdopterin cofactor-containing chicken liver sulphite oxidase, Bioelectrochemistry, in press. 
Foulds, N. C., Wilshere, J. M. and Green, M. J., 1990, Rapid electrochemical assay for theophylline in whole blood based on the inhibition of bovine liver alkaline phosphatase, Anal. Chim. Acta, 229, 57-62.

Fridman, V., Wollenberger, U., Bogdanovskaya, V., Lisdat, F., Ruzgas, T., Lindgren, A., Gorton, L. and Scheller, F. W., 2000, Electrochemical investigation of cellobiose oxidation by cellobiose dehydrogenase in the presence of cytochrome $c$ as mediator, Biochem. Soc. Trans., 28, 63-70.

Ghindilis, A. L., Atanasov, P. and Wilkins, E., 1997, Enzyme-catalyzed direct electron transfer. Fundamentals and analytical applications, Electroanalysis, 9, 661-674.

Gorton, L., Lindgren, A., Larsson, T., Munteanu, F. D., Ruzgas, T. and Gazaryan, I., 1999, Direct electron transfer between heme-containing enzymes and electrodes as basis for third generation biosensors, Anal. Chim. Acta, 400, 91-108.

Gupta, S. K., Agarwal, A. K. and Decastro, A. F., 1988, A novel enzymatic approach for serum theophylline measurement, Clin. Chem., 34, 1267-1267.

Jackson, R. H., Garrido, R., Silverman, H. I. and Salem, H., 1973, Blood levels following oral administration of theophylline preparations, Ann. Allergy, 31, 413-419.

Jin, W., Wollenberger, U., Bier, F. F., Makower, A. and Scheller, F. W., 1996, Electron transfer between cytochrome $c$ and copper enzymes, Bioelectrochem. Bioenerg., 39, 221-225.

Kamin, R. A., Wilson, G. S., 1980 Rotating ring-disk enzyme electrode for biocatalysis kinetic studies and characterization of the immobilized enzyme layer. Anal. Chem. $52,1198-1205$.

Kaplan, A. and Pesce, J., 1984, Clinical Chemistry, The C. V. Mosby Company, St. Louis, MO.

Kawai, M. and Kato, M., 2000, Theophylline for the treatment of bronchial asthma: Present status, Meth. Find. Exp. Clin. Pharmacol. 22, 309-320.

Larsson, T., Lindgren, A. and Ruzgas, T., 2001, Spectroelectrochemical study of cellobiose dehydrogenase and diaphorase in a thiol-modified gold capillary in the absence of mediators, Bioelectrochemistry, 53, 243-249.

Lindgren, A., Larsson, T., Ruzgas, T. and Gorton, L., 2000, Direct electron transfer between the heme of cellobiose dehydrogenase and thiol modified gold electrodes, J. Electroanal. Chem., 494, 105-113.

McNeil, C. J., Cooper, J. M. and Spoors, J. A., 1992, Amperometric enzyme electrode for determination of theophylline in serum, Biosens. Bioelectron., 7, 375-380. 
Rowe, D. J., Watson, I. D., Williams, J. and Berry, D. J., 1988, The clinical use and measurement of theophylline, Ann. Clin. Biochem., 25, 4-26.

Schuhmann, W., Zimmermann, H., Habermüller, K. and Laurinavicius, V., 2000, Electrontransfer pathways between redox enzymes and electrode surfaces: reagentless biosensors based on thiol-monolayer-bound and polypyrrole-entrapped enzymes, Faraday Disc., 245-55.

Shu, F. R., Wilson, G. S., 1976, Rotating ring-disk enzyme electrode for surface catalysis studies. Anal. Chem. 48, 1679-1686.

Stredansky, M., Pizzariello, A., Miertus, S. and Svorc, J., 2000, Selective and sensitive biosensor for theophylline based on xanthine oxidase electrode, Anal. Biochem., $285,225-229$.

Tarasevich, M. R., Yaropolov, A. I., Bogdanovskaya, V. A., 1979, Electrocatalysis of a cathodic oxygen reduction by laccase, Bioelectrochem. Bioeng., 6, 393-403.

Wang, J., Dempsey, E., Ozsoz, M. and Smyth, M. R., 1991, Amperometric enzyme electrode for theophylline, Analyst, 116, 997-999.

Yaropolov, A. I., Malovik, V., Varfolomeev, S. D., Berezin, I. V., 1979, Electroreduction of hydrogen peroxide on an electrode with immobilized peroxidase, Dokl. Akad. Nauk. SSSR, 249, 1399-1401. 
Table 1. Dependence of the steady state current for $1 \mathrm{mM}$ theophylline at a ThO modified electrode on $\mathrm{pH}$. Flow rate: $0.4 \mathrm{ml} / \mathrm{min}$, phosphate buffer $(50 \mathrm{mM})$. Applied potential +0.1 $\mathrm{mV}$ vs. $\mathrm{Ag} \mid \mathrm{AgCl}$.

\begin{tabular}{cc}
\hline $\mathrm{pH}$ & Steady state current/nA \\
6 & 0 \\
7 & 1.2 \\
8 & 0.4 \\
\hline
\end{tabular}




\section{Legends to the figures}

Fig. 1. Schematic representation of spectroelectrochemical gold capillary cell.

Fig. 2. An example of a current response registered with a ThO modified graphite electrode. (A) Buffer baseline, (B) Introduction of buffer containing theophylline, (C) Capacitive anodic peak current due to adsorptive interactions of theophylline with the surface of the electrode, (D) Faradaic steady state current recorded for theophylline, (E) Exchange to plain buffer, (F) Capacitive cathodic peak current due to theophylline desorption from electrode surface. Experimental conditions: phosphate buffer $(50 \mathrm{mM}$, pH7), carrier flow rate $0.4 \mathrm{ml} / \mathrm{min}$, applied potential $+0.1 \mathrm{~V}$ vs. $\mathrm{Ag} \mid \mathrm{AgCl}$.

Fig. 3. The dependence of the steady state current at a ThO modified graphite electrode on the concentration of theophylline in the flow carrier (phosphate buffer: $50 \mathrm{mM}, \mathrm{pH} 7$ ). Applied potential: $+0.1 \mathrm{~V}$ vs. $\mathrm{Ag} \mid \mathrm{AgCl}$. Flowrate: $0.4 \mathrm{ml} / \mathrm{min}$. The error bars show 95\% confidence intervals of the estimated values.

Fig. 4. Postulated reaction sequence for theophylline oxidation at a ThO modified graphite electrode.

Fig. 5. Electrochemical redox conversion of $\mathrm{ThO}$ from its oxidised (at $0 \mathrm{~V}$ ) to reduced (at $0.6 \mathrm{~V}$ ) form due to direct (mediatorless) electron transfer between the enzyme and the aldrithiol-modified gold electrode. Time lap is about 90 min between the first (at $-0.6 \mathrm{~V}$ ) and last (at $0 \mathrm{~V}$ ) spectrum. Insert: spectra of oxidised and reduced cyt. $c$ recorded at +0.3 and -0.3 $\mathrm{V}$, respectively. 
Fig. 6. Electrochemical titration plots recorded for cyt. $c$ and ThO solution in the gold capillary of the spectroelectrochemical cell. The lines are linear regressions of all points by Nernst equation with the result for cyt. $c: n=0.93$ and $E^{\circ}=0.068 \mathrm{~V}$; and ThO: $n=0.53$ and $E^{\circ}=-0.275 \mathrm{~V}$. Potentials are reported vs. $\mathrm{Ag} \mid \mathrm{AgCl}$ sat. The proteins were dissolved in $0.02 \mathrm{M}$ phosphate buffer solution ( $\mathrm{pH} 7.0$ ) containing $0.1 \mathrm{M} \mathrm{KCl}$. 


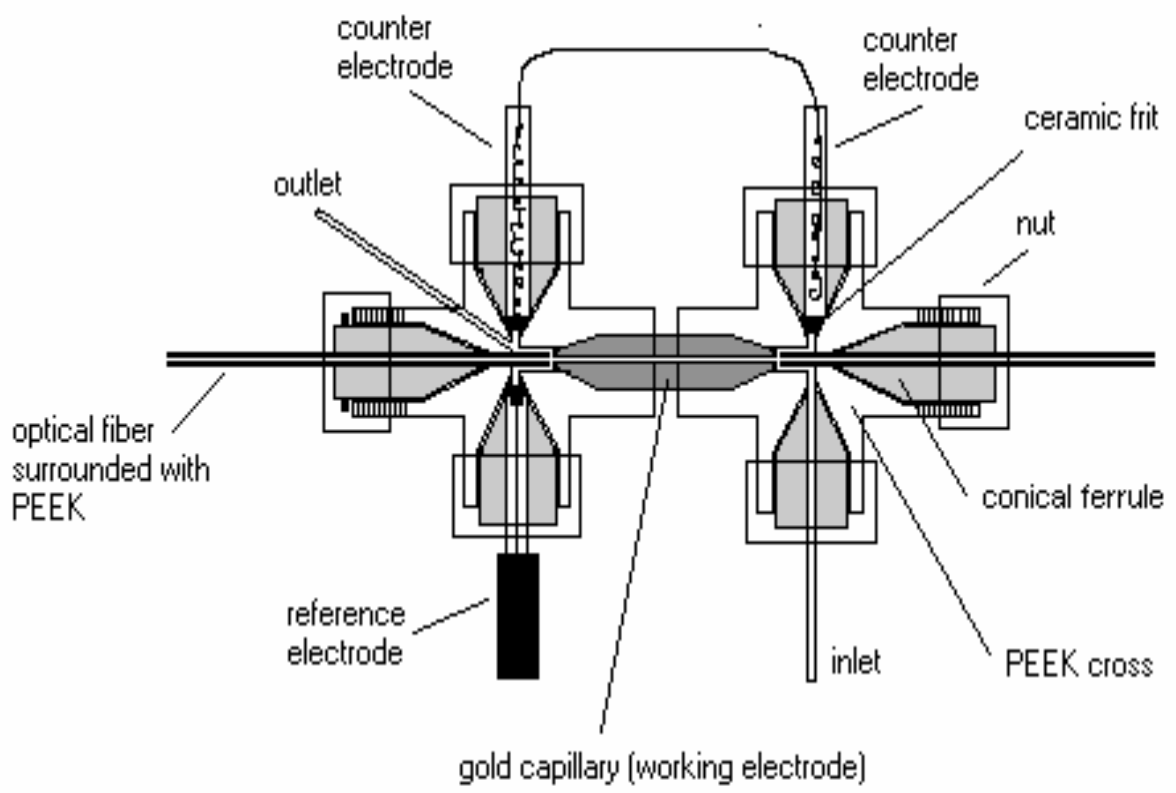

Fig. 1 


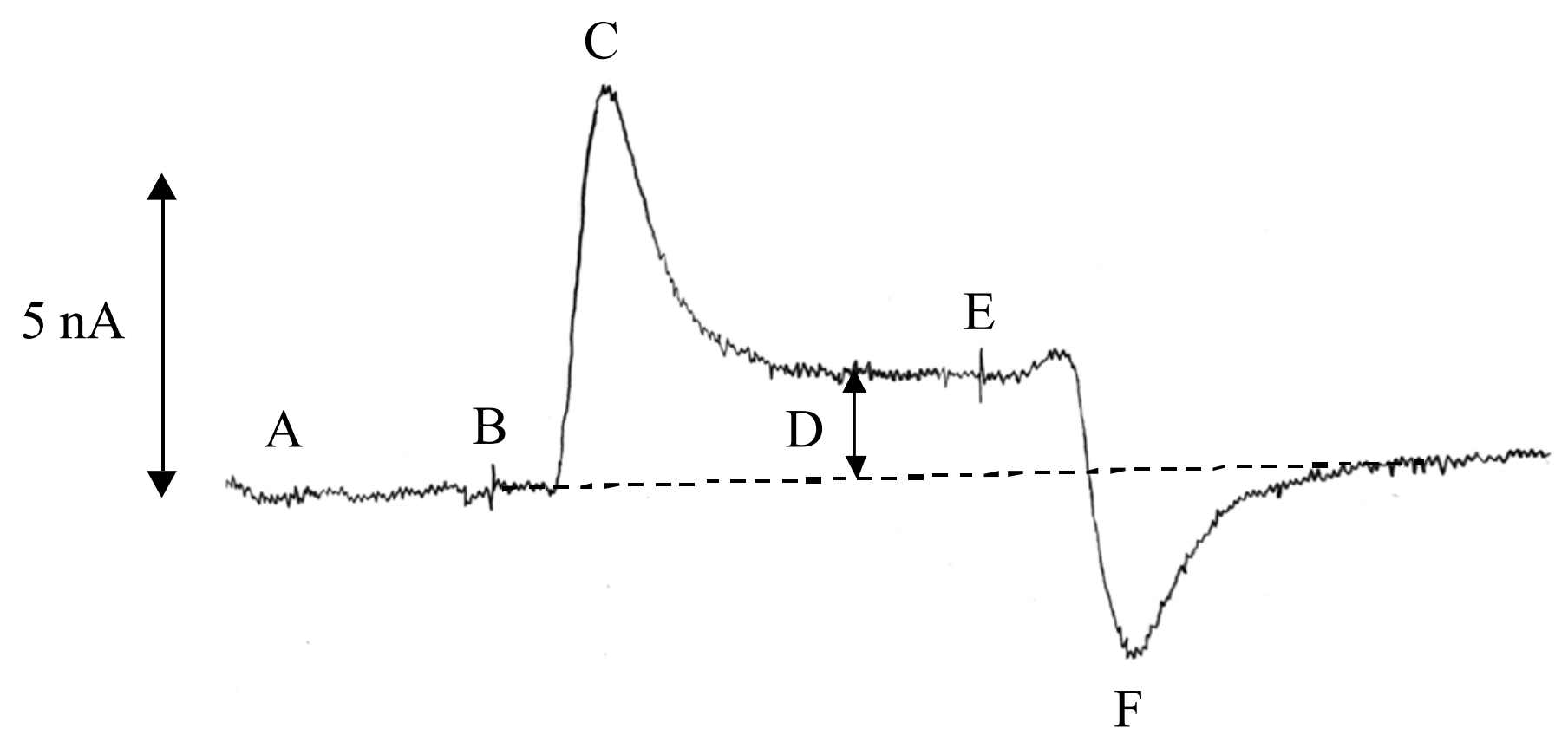

$10 \mathrm{~min}$

Fig. 2 


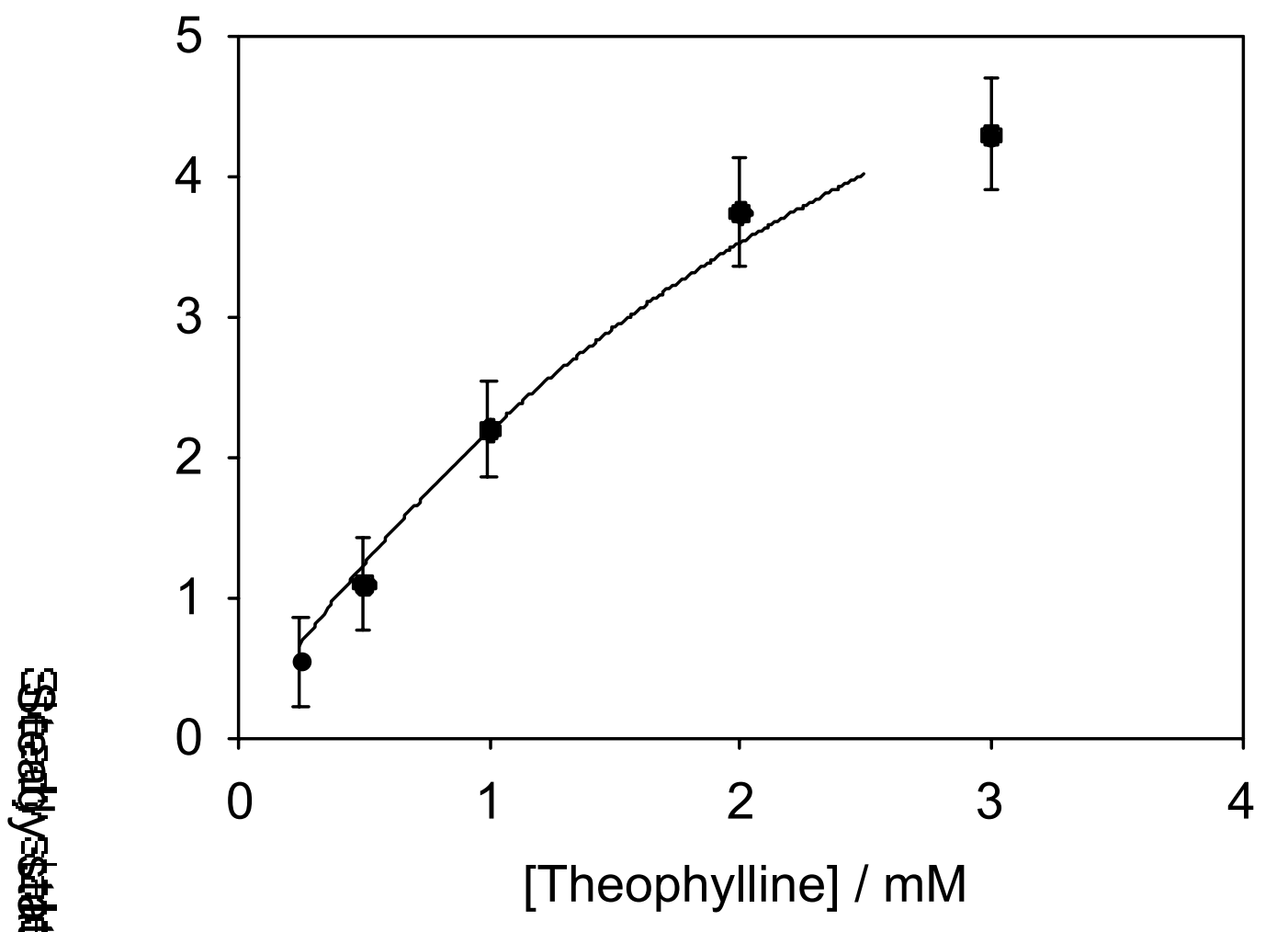

